\title{
Deaktivasi Katalis Konverter-Hidrogen Di Pabrik Urea Kaltim-3
}

\author{
Agus Subekti 1), Achmad Syamsul Arief 1), Praharso1), Subagjo 2) *) \\ 1) PT. Pupuk Kalimantan Timur : sbekti@pupukkaltim.com, \\ 2)Program Studi Teknik Kimia, Fakultas Teknologi Industri, ITB: subagjo@che.itb.ac.id
}

Presented at Symposium and Congress of MKICS 2007, 18-19 April 2007, Semarang, Indonesia

\begin{abstract}
Di pabrik urea, konverter-hidrogen adalah satu reaktor yang berfungsi untuk mengkonversi hidrogen yang terikut dalam karbondioksida dengan cara mengoksidasi dengan udara, sehingga karbondioksida umpan reaktor urea itu hanya mengandung tidak lebih dari 100 ppm hidrogen. Konversi dilangsungkan pada tekanan $145 \mathrm{~kg} / \mathrm{cm}^{2}$ dan suhu umpan reaktor $130^{\circ} \mathrm{C}$, menggunakan katalis platinum berpenyangga alumina $\left(0,3 \% \mathrm{Pt} / \mathrm{Al}_{2} \mathrm{O}_{3}\right)$. Dalam dua tahun terakhir, terjadi kenaikan kandungan hidrogen dalam karbondioksida umpan konverter-hidrogen Kaltim-3 yang menyebabkan peningkatan temperatur keluaran konverter dari biasanya sekitar $152^{\circ} \mathrm{C}$ menjadi sekitar $190^{\circ} \mathrm{C}$. Hasil analisis kadar $\mathrm{Pt}$, luas permukaan katalis dan dispersi Pt terhadap katalis-baru dan katalis-terpakai menunjukkan bahwa katalis konverter-hidrogen Kaltim-3 telah terdeaktivasi. Oleh karena itu, pada kesempatan perbaikan-tahunan Juli 2006 yang lalu, katalis tersebut telah diganti dengan yang baru. Selain itu telah dilakukan pula perbaikan kondisi operasi di pabrik amoniak Kaltim-3, sehingga kadar $\mathrm{H}_{2}$ dalam aliran $\mathrm{CO}_{2}$ umpan pabrik urea Kaltim-3 menjadi normal kembali (0,4\%). Dengan tindakan-tindakan tersebut, sejak Agustus 2006 yang lalu konverterhidrogen Kaltim-3 dapat beroperasi secara normal kembali. (c) 2007 CREC UNDIP. All rights reserved.
\end{abstract}

Keywords: : Deaktivasi,konverter- hidrogen, platinum, urea, sintering

Pabrik urea dapat dibagi dalam 4 unit, yaitu unit sintesis, resirkulasi, finishing dan waste water treatment. Pembentukan urea terjadi pada unit sintesis melalui reaksi utama sebagai berikut:

$$
\begin{aligned}
& 2 \mathrm{NH}_{3}(\mathrm{l})+\mathrm{CO}_{2}(\mathrm{~g}) \quad \leftrightarrow \quad \mathrm{NH}_{2} \mathrm{CONH}_{4}(\mathrm{l})+28,5 \\
& \mathrm{kcal} / \mathrm{mol} \\
& \mathrm{NH}_{2} \mathrm{CONH}_{4}(\mathrm{l}) \quad \leftrightarrow \quad \mathrm{NH}_{2} \mathrm{CONH}_{2}(\mathrm{l})+ \\
& \mathrm{H}_{2} \mathrm{O} \text { (l) }-4 \mathrm{kcal} / \mathrm{mol}
\end{aligned}
$$

Secara ringkas proses yang terjadi pada unit sintesis (gambar 1) dapat diuraikan sebagai berikut. Amoniak cair, setelah digunakan untuk menarik larutan karbamat hasil daur ulang,

*) Corresponding Author.

E-mail address: subagjo@che.itb.ac.id (Subagjo) diumpankan ke High Pressure Carbamat Condensor (HPCC). Di sisi lain, gas $\mathrm{CO}_{2}$ mulamula diumpankan ke dalam konverter-hidrogen untuk menyingkirkan $\mathrm{H}_{2}$ yang dikandungnya, kemudian digunakan di High Pressure Stripper (HP Stripper) untuk melucuti (stripping) sisa reaktan yang terdapat dalam keluaran reaktor urea, selanjutnya dipertemukan dengan amoniak cair di HPCC. Pembentukan urea terutama (80\%) terjadi di dalam HPCC, dan sisanya (20\%) berlangsung di dalam reaktor urea. Sisa reaktan dan karbamat kemudian dipisahkan, sehingga 


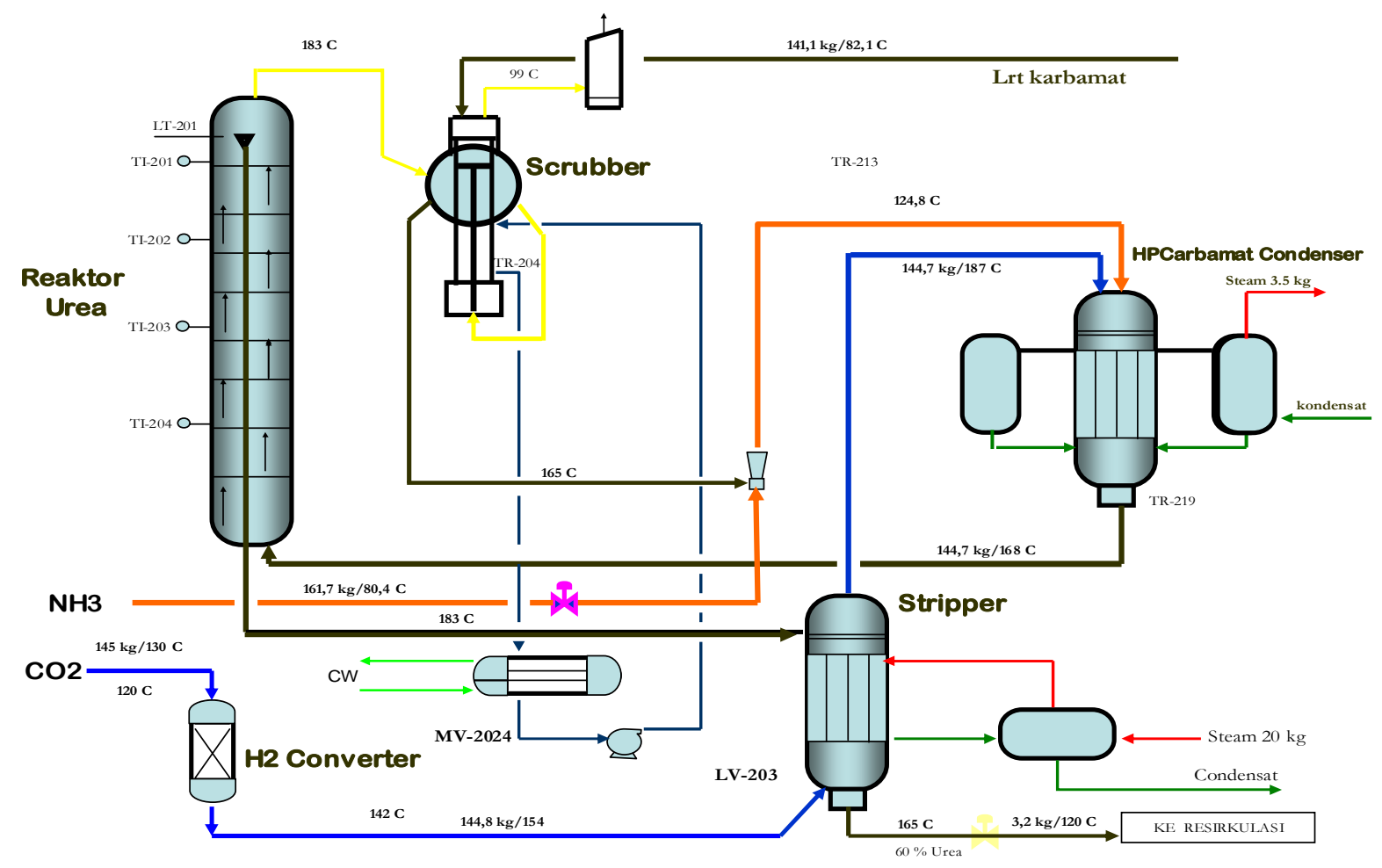

Gambar 1 : Unit Sintesis Pabrik Urea Kaltim-3

diperoleh larutan-pekat urea.

Dalam kurun waktu 2 tahun terakhir (2004 s/d 2006), kinerja konverter-hidrogen pabrik urea Kaltim-3 mengalami perubahan yang cukup besar. Temperatur keluaran konverter yang biasanya hanya berkisar $152^{\circ} \mathrm{C}$, meningkat hingga $190^{\circ} \mathrm{C}$. Hal ini terjadi karena kandungan hidrogen dalam gas karbondioksida umpannya, yang berasal dari pabrik amoniak Kaltim-3, mengalami kenaikan dari keadaan normal 0,4 \% menjadi $1,4 \%$.

Dalam makalah ini didiskusikan cara evaluasi keadaan katalis konverter-hidrogen yang telah dioperasikan pada kondisi tidak wajar selama waktu yang relatif panjang seperti diuraikan di atas.

\section{Konverter-hidrogen}

Konverter-hidrogen adalah satu peralatan di pabrik urea yang berfungsi untuk mengkonversi hidrogen yang terikut dalam karbondioksida $\left(\mathrm{CO}_{2}\right)$ dari pabrik amoniak dengan cara mengoksidasinya dengan udara. Reaksi yang terjadi adalah reaksi sangat eksotermis sebagai berikut.

$$
2 \mathrm{H}_{2}+\mathrm{O}_{2} \leftrightarrow 2 \mathrm{H}_{2} \mathrm{O} \quad \Delta \mathrm{H}^{\mathrm{o}}{ }_{298}=-57,8 \mathrm{kcal} / \mathrm{mol}
$$

Konverter-hidrogen berupa bejana reaktor berisi unggun katalis yang tersusun dari: bagian paling atas adalah ceramic ball $13 \mathrm{~mm}$ sebanyak $0,1 \mathrm{~m}^{3}$, dibawahnya adalah katalis berbasis Pt sebanyak $1,0 \mathrm{~m}^{3}$, dan bagian paling bawah adalah ceramic ball $6 \mathrm{~mm}$ sebanyak $0,1 \mathrm{~m}^{3}$.

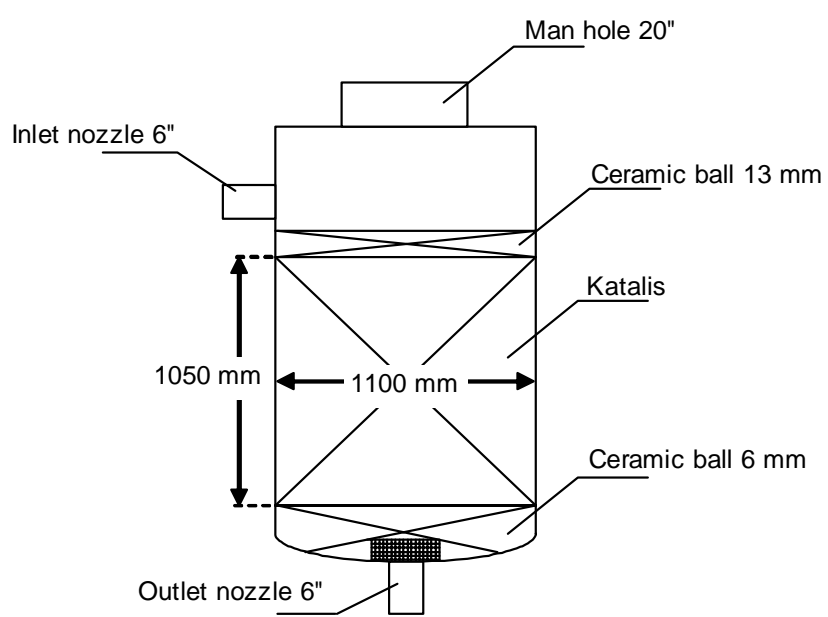

Katalis konverter-hidrogen yang termuat dan dioperasikan sejak Oktober 2001 memiliki spesifikasi, sesuai data vendor, sebagai berikut :

Katalis $\quad: 0.3 \% \mathrm{Pt}$ berpenyangga $\mathrm{B}-\mathrm{Al}_{2} \mathrm{O}_{3}$

Ukuran partikel : Tablet $3 \times 3 \mathrm{~mm}$

Luas permukaan katalis: 100 m²/g katalis 
Luas Permukaan Pt

Volum pori makro

Densitas bulk

Temperatur maksimum

Kecepatan linier

Pada kondisi normal, gas $\mathrm{CO}_{2}$ umpan yang mengandung sekitar $0,4 \% \quad \mathrm{H}_{2}$ masuk ke dalam konverter pada temperatur $130^{\circ} \mathrm{C}$ dan tekanan $145 \mathrm{~kg} / \mathrm{cm}^{2}$. Gas keluar konverter biasanya bertemperatur sekitar $150^{\circ} \mathrm{C}-155^{\circ} \mathrm{C}$, dan hanya mengandung $100 \mathrm{ppm} \quad \mathrm{H}_{2}$. Temperatur maksimum keluaran yang diijinkan adalah $260^{\circ} \mathrm{C}$ untuk mencegah kerusakan bejana.

Dalam 2 tahun terakhir, konverterhidrogen Kaltim-3 telah bekerja pada kondisi keras, akibat kenaikan kandungan hidrogen dalam gas karbondioksida umpannya dari biasanya $0,4 \%$ menjadi $1,4 \%$. Keadaan ini menyebabkan temperatur keluaran reaktor meningkat, sehingga selisih suhu keluaran dan masukan $(\Delta \mathrm{T})$ yang biasanya hanya berkisar $22^{\circ} \mathrm{C}$, meningkat menjadi $60^{\circ} \mathrm{C}$. Kondisi seperti ini belum pernah terjadi sepanjang beroperasinya pabrik urea Kaltim-3, yang telah memasuki usianya yang ke-18 tahun pada tahun 2006.

Selama 18 tahun beroperasi itu, katalis konverter-hidrogen pabrik urea Kaltim-3, baru mengalami penggantian 2 kali, yaitu: pengisian pertama pada tahun 1988, kemudian penggantian katalis pada tahun 2001. Katalis pertama yang bekerja pada kondisi normal dapat berusia sampai 13 tahun. Katalis kedua, pada 2006 ini baru berusia 5 tahun, tetapi seperti diuraikan di atas, selama dua tahun terakhir telah terus-menerus bekerja pada kondisi yang relatif berat. Dikhawatirkan katalis telah terdeaktivasi akibat bekerja dalam waktu yang panjang pada temperatur yang tinggi $\left(40^{\circ} \mathrm{C}\right.$ lebih tinggi dari keadaan normal). Pada temperatur tinggi katalis konverter-hidrogen dapat mengalami sintering. Oleh karena itu pada kesempatan turn-around Juli 2006 telah dilakukan evaluasi terhadap keadaan katalis untuk menjawab pertanyaan:" Apakah katalis masih dapat bekerja sesuai target hingga turnaround mendatang?".

\section{Karakterisasi Katalis}

Jika katalis (konverter-hidrogen) telah mengalami sintering, maka luas permukaan katalis dan/atau luas permukaan platina akan menjadi lebih kecil. Oleh karena itu, untuk tujuan evaluasi keadaan katalis konverterhidrogen pabrik urea Kaltim-3, perlu dilakukan beberapa analisis/pengukuran beberapa sifat katalis, yaitu [2]:
- kadar Pt pada katalis-baru dan katalisterpakai

- luas permukaan dari katalis-baru dan katalisterpakai

- luas permukaan Pt dari katalis-baru dan katalis-terpakai

- ukuran kristal Pt di permukaan katalis-baru dan katalis-terpakai

Katalis-terpakai diwakili oleh katalis pada bagian atas dan bawah unggun, masing-masing sebanyak $1 \mathrm{~kg}$.

Kecuali penentuan ukuran kristal Pt di permukaan katalis yang tidak dilakukan, analisis tiga sifat yang lain dilakukan di Laboratorium Unit Penelitian dan Laboratorium, Direktorat Pengolahan, Pertamina di Pulogadung Jakarta. Analisis kadar Pt dilakukan dengan XRF (X-Ray Fluorescence), pengukuran luas permukaan spesifik katalis dilakukan menggunakan metoda ASTM-3663 dan pengukuran luas permukaan Pt (diwakili dengan dispersi $\mathrm{Pt}$ ) dilakukan dengan adsorpsi kimia hidrogen pada katalis. Ukuran partikel Pt dapat ditentukan menggunakan TEM (Transmission Electron Microscopy), atau menggunakan XRD (X-Ray Diffraction) untuk ukuran kristal 5-50 nm [3,4].

\section{Hasil dan Pembahasan}

Evaluasi dikerjakan bersama oleh praktisi katalisis dari industri dan perguruan tinggi (PT Pupuk Kaltim dan Program Studi Teknik Kimia ITB), mencakup: pemilihan dan pengambilan sample katalis, pemilihan sifat katalis yang dianalisis, metode analisis dan cara evaluasi hasil analisis. Hasil analisis beberapa sifat katalis konverter-hidrogen pabrik urea Kaltim-3 ditampilkan pada tabel 1 berikut ini.

Tabel 1: Beberapa Sifat Katalis Konverter hidrogen Pabrik Urea Kaltim-3

\begin{tabular}{|l|l|l|l|}
\hline \multirow{2}{*}{ Sifat Katalis } & \multirow{2}{*}{$\begin{array}{l}\text { Katalis- } \\
\text { baru }\end{array}$} & \multicolumn{2}{|l|}{ Katalis-terpakai } \\
\cline { 3 - 4 } & $\begin{array}{l}\text { Bagian } \\
\text { Atas }\end{array}$ & $\begin{array}{l}\text { Bagian } \\
\text { Bawah }\end{array}$ \\
\hline Kadar Pt, \%-b & 0,35 & 0,35 & 0,34 \\
\hline $\begin{array}{l}\text { Luas Permukaan, } \\
\mathrm{m}^{2} / \mathrm{g}\end{array}$ & 95,7 & 83,8 & $\begin{array}{l}\text { tidak } \\
\text { dianalisis }\end{array}$ \\
\hline Dispersi Pt, \%-b & 82,6 & 12,5 & 41 \\
\hline
\end{tabular}

Hasil tersebut menunjukkan bahwa kadar Pt dan luas permukaan spesifik katalis-baru dan katalis-terpakai tidak terlalu berbeda, tetapi dispersi Pt pada permukaan alumina katalisterpakai jauh lebih kecil daripada katalis-baru. Penurunan luas permukaan katalis, meskipun tidak terlalu besar, dapat menunjukkan bahwa penyangga katalis juga mengalami sedikit sintering. 
Dispersi dapat didefinisikan sebagai bagian atau persen Pt yang dapat berperan aktif dalam reaksi. Jadi penurunan dispersi $\mathrm{Pt}$ selama penggunaan katalis memberi indikasi bahwa:

- katalis telah terdeaktivasi; aktivitas katalisterpakai di bagian atas unggun tinggal 1/7 aktivitas katalis-baru, sedangkan aktivitas katalis-terpakai di bagian bawah unggun masih $1 / 2$ aktivitas katalis-baru.

- deaktivasi terutama disebabkan oleh aglomerasi (sintering) Pt di permukaan alumina.

Aglomerasi fasa aktif logam mulia (termasuk Pt) yang terdispersi di permukaan penyangga dipercepat oleh peningkatan tekanan parsial air, temperatur, waktu atau kombinasi dari faktorfaktor tersebut. Peningkatan kadar hidrogen tidak saja menyebabkan peningkatan temperatur reaksi, tetapi juga tekanan parsial air. Terlebih-lebih keadaan ini telah berlangsung dalam kurun waktu yang panjang. Bisa jadi, konversi hidrogen terutama terjadi pada sebagian kecil lapisan atas unggun katalis, menghasilkan kalor yang besar, dan menyebabkan peningkatan temperatur di lapisan tersebut, sehingga mencapai nilai yang cukup tinggi untuk terjadinya sintering fasa aktif platina. Dengan keadaan katalis yang seperti itu (lihat tabel 1), dikhawatirkan konverter-hidrogen tidak dapat bekerja sesuai target hingga masa turn-around yang akan datang (dalam 2 tahun mendatang). Berdasarkan kenyataan tersebut, telah direkomendasikan beberapa hal berikut.

- Katalis terpasang harus segera diganti, agar target penyingkiran hidrogen selalu dapat dicapai dalam kurun waktu yang panjang.

- Katalis-baru yang tersedia hanya $0,8 \mathrm{~m}^{3}$, maka katalis-baru diletakkan di bagian bawah unggun katalis dalam reaktor; dan kekurangannya $\left(0,2 \mathrm{~m}^{3}\right)$ dipenuhi dengan katalis-terpakai yang diambil dari bagian bawah unggun katalis-terpakai dalam konverter. Konfigurasi (susunan) katalis seperti ini akan memberikan distribusi temperatur di dalam reaktor lebih merata. Umpan yang kaya akan $\mathrm{H}_{2}$ mula-mula akan kontak dengan katalis-bekas menghasilkan konversi dan kalor yang tidak terlalu tinggi, dan katalis-baru akan hanya kontak dengan gas miskin $\mathrm{H}_{2}$, sehingga menghasilkan kalor yang juga tidak terlalu tinggi. Selain itu konfigurasi seperti ini dapat menjamin kadar $\mathrm{H}_{2}$ lebih rendah dari pada konfigurasi yang lain.

- Penyebab peningkatan kadar $\mathrm{H}_{2}$ di dalam umpan harus segera diatasi agar deaktivasi katalis tidak terulang kembali.
Penggantian katalis telah dilaksanakan pada akhir Juli 2006. Meskipun demikian konverterhidrogen belum beroperasi normal, karena kandungan hidrogen dalam gas $\mathrm{CO}_{2}$ masih relatif tinggi, yaitu $1,2 \%$. Selisih temperatur pada gerbang masuk dan keluar konverter-hidrogen belum mengalami perubahan, masih berkisar $50^{\circ}$ C. Namun setelah dilakukan perbaikan kondisi operasi di pabrik amoniak, sehingga kadar $\mathrm{H}_{2}$ di dalam aliran gas $\mathrm{CO}_{2}$ menjadi kembali normal $(\sim 0,4 \%)$, selisih temperatur aliran umpan dan keluaran konverter-hidrogen dapat mencapai sekitar $22^{\circ} \mathrm{C}$. Dengan beroperasi normal seperti itu, diharapkan katalis konverter-hidrogen pabrik urea Kaltim-3 dapat berumur tidak kurang dari 10 tahun, seperti katalis yang dimuatkan pertama.

\section{Kesimpulan}

Dari hasil analisis dan pembahasan di atas dapat disimpulkan bahwa, katalis konverterhidrogen $\quad\left(0.3 \% \quad \mathrm{Pt} / \mathrm{B}-\mathrm{Al}_{2} \mathrm{O}_{3}\right) \quad$ Kaltim-3 telah terdeaktivasi akibat dioperasikan pada temperatur tinggi (meskipun tidak terlalu tinggi) dalam jangka waktu yang panjang. Deaktivasi terutama disebabkan oleh terjadinya aglomerasi fasa aktif $\mathrm{Pt}$ di permukaan alumina. Pengalaman ini memberi pelajaran agar evaluasi kinerja katalis harus selalu dilakukan secara seksama untuk merencanakan operasi/tindakan yang tepat. Kerjasama antar praktisi dari perguruan tinggi, lembaga penelitian dan industri dapat memberi manfaat yang sangat berarti bagi semua pihak, dan oleh karenanya perlu digalakkan

\section{Ucapan Terima Kasih}

Para penulis mengucapkan terima kasih kepada: Direksi dan Manajemen PT. Pupuk Kaltim atas dukungannya, Kepala Unit Kerja Departemen Operasi Kaltim-3 dan Biro Teknologi atas segala bantuannya, dan teman-teman dari $\mathrm{P}$ \& L Direktorat Pengolahan Pertamina yang telah membantu melaksanakan karakterisasi katalis.

\section{Daftar Pustaka}

1. Team Start Up, Petunjuk Operasi Pabrik Urea Kaltim-3, 1988.

2. Pernicone N., (1985), Appl. Catal., 15, hal. $17-$ 31.

3. J. T. Richardson, Principles of Catalyst Development, Plenum Press, New York, 1989.

4. C. N. Satterfield, Heterogeneous Catalysis in Industrial Practice, 2 $2^{\text {nd }}$ ed., Mc Graw Hill, 1991. 